\title{
A MEDIAÇÃO FAMILIAR E O FIM DO RELACIONAMENTO CONJUGAL: O PROBLEMA DO ACESSO À JUSTIÇA E A EXPERIÊNCIA DAS OFICINAS DE PARENTALIDADE
}

\author{
Marcella Mourão de Brito ${ }^{1}$ \\ Alexandre Antônio Bruno da Silva ${ }^{2}$
}

\section{RESUMO}

O presente artigo objetiva discorrer sobre as mudanças sociais relacionadas à família, verificando o surgimento do conflito na ausência de diálogo na família. Examinar a importância da mediação na melhoria do diálogo no fim do relacionamento conjugal, já que a ruptura na relação familiar ocasiona o sofrimento em todos os envolvidos no litígio. Contextualizar o aumento da demanda judicial com o problema do acesso à justiça. Apresentar a experiência pioneira das oficinas de parentalidade, que utilizam técnicas da mediação de conflitos, para auxiliar no diálogo em divórcios conturbados, baseando o estudo em pesquisa de campo, bibliografia e dados governamentais.

Palavras-chave: Conflito. Dinâmica familiar. Divórcio litigioso. Mediação. Oficinas de Parentalidade.

\section{FAMILY MEDIATION AND THE END OF CONJUGAL RELATIONSHIP (OR LITIGIOUS DIVORCE?): THE PROBLEM OF ACCESS TO JUSTICE AND THE EXPERIENCE OF PARENTALITY WORKSHOPS}

\begin{abstract}
This article aims to discuss social changes related to the family, verifying the emergence of conflict in the absence of dialogue in the family. To examine the importance of mediation in improving dialogue at the end of the marital relationship, since the rupture in the family relationship causes suffering in all those involved in the litigation. Contextualize the increase of the judicial demand with the problem of access to justice. To present the pioneering experience of parenting workshops, using conflict mediation techniques, to aid dialogue in troubled divorces, basing study on field research, bibliography, and government data.
\end{abstract}

Keywords: Conflict. Family dynamics. Litigious divorce. Mediation. Parenting workshops.

\footnotetext{
${ }^{1}$ Mestranda em Processo e Direito ao Desenvolvimento pelo Centro Universitário Christus (UNICHRISTUS). Especializanda em Mediação e Gestão de Conflitos (UNIFOR). Especialização em Direito Processual Civil (ANHANGUERA/UNIDERP). Inscrita na Ordem dos Advogados Seção Ceará sob o no 23.459. Graduação em Direito pela Universidade de Fortaleza (2009). E-mail: marcellamouraob@gmail.com

${ }^{2}$ Doutor em Direito pela PUC-SP. Mestre em Direito pela UFC. Mestre em Informática pela PUC-RJ. Professor do Programa de Pós-Graduação stricto sensu do Centro Universitário Christus. Professor Adjunto da Universidade Estadual do Ceará (UECE). Auditor-Fiscal do Trabalho. E-mail: alexandre.bruno@ @erra.com.br.
} 


\section{INTRODUÇÃO}

O núcleo familiar, com as diversas mudanças sociais, passa por grandes transformações, assumindo diversas feições. O estudo do fenômeno da parentalidade passa a ser prioridade na análise das relações familiares, dando novas feições e novas atribuições aos integrantes das famílias.

As mudanças na dinâmica familiar originam conflitos interpessoais, principalmente com as novas atribuições abarcadas pelas mulheres na sociedade. Os filhos, adolescentes e crianças, passaram a questionar e a negociar de maneira incisiva, fatos que, geralmente, não aconteciam em situações em que o modelo familiar prevalente era o patriarcal, época em que o pai limitava-se a mandar, enquanto a mulher e os filhos a obedecer.

A ausência de comunicação e de diálogo no seio familiar pode trazer diversas consequências. Uma delas, o fim de um relacionamento conjugal, envolve todos os familiares, principalmente crianças e adolescentes. Os conflitos oriundos da separação em si, pela guarda ou até devido a algum impasse financeiro, podem gerar diversas sequelas na formação da criança e do adolescente, de maneiras diversas e imprevisíveis.

Muitas vezes, por mágoas causadas pelo rompimento, os pais assumem posição de acirramento, competição, frustração, decepção, tristeza, insegurança, raiva e desesperança. A falta de entendimento é refletida no relacionamento com os filhos, que acabam por absorver a pesada carga emocional, gerada pela ausência de diálogo, a qual lhes foi imposta. Dessa forma, a ruptura do vínculo conjugal termina por implicar em traumas e consequências emocionais que podem perdurar por muito tempo em suas vidas.

A mediação mostra-se como um importante método de melhoria da qualidade do diálogo entre as partes envolvidas no conflito. Por meio de ferramentas, como a empatia, a responsabilização das partes pelos problemas que enfrentam e a validação de sentimentos, é possível demonstrar às partes que elas são capazes de construir o diálogo entre si e, oportunamente, obter uma resolução pacífica para o problema.

Imbuído do movimento de impulsionar a valorização da busca pelo consenso, o Conselho Nacional de Justiça (CNJ) encampou e adotou como política institucional, de acordo com a Recomendação n 50 de 08/05/2014, a Oficina de Parentalidade. Este é um Projeto pioneiro, que nasceu inspirado em técnicas utilizadas em países como o Canadá e os Estados Unidos, cuja finalidade é reunir, em encontros quinzenais ou mensais, famílias que passam por 
processos de ruptura conjugal, dentre outros litígios, auxiliando pais e filhos a dialogarem de maneira aberta e livre.

A justificativa deste trabalho se dá pelo reconhecimento do valor que o diálogo e a comunicação compassiva demonstram, quando utilizados para auxiliar os envolvidos em um fim de relacionamento conjugal, a lidar de maneira menos traumática e mais pacífica com as mudanças, nos casos em que, muitas vezes, a mágoa, o arrependimento, o orgulho ou a culpa, dentre outros sentimentos, podem inviabilizar o diálogo entre os envolvidos no litígio.

O trabalho desenvolvido pelas oficinas de parentalidade, que utiliza técnicas da mediação para estimular as partes a lidar com a nova configuração familiar, iniciou em São Paulo. Devido ao seu resultado positivo, espalhou-se pelo Brasil e já é realizado em diversos Tribunais brasileiros. O projeto sediado em Fortaleza, Ceará, tornou-se exemplo de qualidade para todo o país, recebendo servidores de outros estados para realizar treinamento.

Em relação à metodologia utilizada, ressalta-se que o presente trabalho foi fruto de uma vivência realizada em visita ao CEJUSC (Centro Judiciário de Solução de Conflitos) de Fortaleza, pela participação como ouvinte e estudante em uma das oficinas de parentalidade, oferecidas à época. As informações trazidas são produto de diálogo com os Juízes José Mauro Lima Feitosa, coordenador das varas de Família e Sucessões da comarca de Fortaleza/CE, e Natália Almino Gondim, responsável pelo setor (CEJUSC), e servidores que participam das oficinas. Tal experiência ensejou o desejo pela pesquisa e discussão sobre o tema. Foram disponibilizados dados pelo Tribunal de Justiça do Estado do Ceará, bem como foram utilizados dados de órgãos oficiais, disponíveis em sítios de internet e bibliografia pertinente ao tema.

\section{AS MUDANÇAS NA DINÂMICA FAMILIAR: NOVOS PAPÉIS, AUSÊNCIA DE DIÁLOGO E SURGIMENTO DO CONFLITO. A BUSCA PELO PODER JUDICIÁRIO}

A família é a base da construção do caráter e desenvolvimento do ser humano. Sua organização representa o seio que estrutura a formação de um indivíduo. No ambiente familiar serão solidificados valores como educação, proteção, segurança, dentre outros, essenciais para à formação de um indivíduo. É a partir do desenvolvimento e da dinâmica desta família que se solidificam os deveres e as obrigações atribuídos e distribuídos para cada membro familiar.

Nas famílias do século XX, os papéis eram divididos mesmo antes do casamento e do nascimento dos filhos. A figura paterna era o centro das decisões, em posição de hierarquia superior à da esposa e dos filhos, que se renegavam ou se contentavam em obedecer às diretrizes 
deste patriarca. O modelo que prevalecia na sociedade era somente o modelo familiar advindo por ocasião de casamento religioso, baseado na indissolubilidade. Com o avançar do tempo e as mudanças constantes da sociedade, surgiu a família pós-moderna do século XXI, na qual a dinâmica familiar tomou novas formas. Mulheres e homens tornaram-se possuidores de iguais direitos e deveres na sociedade conjugal, assim como os filhos assumiram posição de igualdade na família e passaram a ser membros familiares com opinião, desejos e poder de influência em pé de igualdade com seus pais.

Para Bauman (2001), vivencia-se a modernidade líquida. A extraordinária mobilidade e disponibilidade de mudança caracteriza tal sociedade fluida, em que a família está diretamente inserida, pois ela, como uma instituição que é, está sendo afetada pela enxurrada de informações e pelo rompimento de barreiras impostas pela sociedade líquida. Padrões, regras e códigos foram quebrados sem nenhum molde que pudesse ser substituído por outro.

Diante da realidade da modernidade líquida (BAUMAN, 2001), as mudanças nos rearranjos familiares, principalmente através da possibilidade de dissolubilidade do casamento e a pluralidade familiar, ensejaram novos modelos familiares. $\mathrm{O}$ afeto passou a ser requisito essencial no reconhecimento das famílias. (SALES, 2007). Gagliano e Pamplona Filho (2017, p.47) denominam esse fenômeno de "blended families" ou recombinação familiar. Além da família matrimonial clássica, a nova parentalidade trouxe novos arranjos, como a informal, a monoparental, a anaparental, a homoafetiva, a unipessoal, a mosaico, a socioafetiva, a paralela, dentre outras formas de organização que consolidaram os direitos garantidos pela Constituição da República Federativa do Brasil de 1988, principalmente o princípio dignidade da pessoa humana.

Para melhor entendimento, define-se família anaparental como aquela formada por parentes e pessoas com interdependência afetiva, sem a presença de pai ou mãe, como por exemplo, grupo de irmãos; família homoafetiva: aquela composta por pessoas do mesmo sexo; família mosaico: a constituída pela junção de duas famílias anteriores, reunindo filhos advindos de outras relações em um núcleo só; família socioafetiva: composta por pessoas não aparentadas entre si; famílias paralelas: quando existem conjugalidades simultâneas; e, por fim, a unipessoal, formada por apenas uma pessoa.

Diante de tantas alterações na dinâmica da família pós-moderna, com a ausência de papéis predeterminados, é natural que as pessoas se sintam perdidas e com dificuldade de encaixe nos modelos modernos. Não há mais a rígida segurança que existia nas famílias de gerações passadas, em que cada membro familiar sabia exatamente quais as suas obrigações, 
direitos e deveres. Passou a ser comum que os membros da família comecem a negociar, questionar e discutir as suas diferenças.

\begin{abstract}
A convivência íntima, durante anos de casamento, entre o casal e entre pais e filhos advindos dessa união gera normas de comportamento, implícitas e explícitas, valores, crenças, mitos, comprometimentos e compromissos. Essas pessoas vivem uma interdependência financeiro-econômica e uma interdependência afetiva, têm necessidades recíprocas e estão ligadas por compromissos de lealdade. De alguns desses aspectos elas têm consciência; de outros, não. (CEZAR-FERREIRA, 2007, p. 63)
\end{abstract}

Surge aí um terreno fértil para o conflito, que é natural ao desenvolvimento humano. Na construção de vínculos, é necessário discutir as situações, palavras ditas, não ditas, olhares, gestos, ações e omissões do dia a dia. (SALES, 2007). Porém, como conflitos familiares envolvem sentimentos bastante complexos, é muito comum que as partes permaneçam discutindo em torno de conflitos aparentes, escondendo o conflito real ${ }^{3}$. Trata-se de um mecanismo de defesa, em que se busca esconder insegurança e vulnerabilidade.

A grande influência de meios digitais, internet e novas dinâmicas escolares, dentre diversos outros fatores, dificulta sobremaneira a comunicação entre os membros familiares, o que prejudica a construção de um lar estável e ancorado em valores, e fomenta o conflito e o distanciamento. Como consequência, aumentam visivelmente os conflitos no seio familiar.

Casamentos se desfazem, surgem as disputas pela guarda dos filhos, dentre outros diversos desalinhos que, inclusive, comprometem a boa convivência com os demais integrantes da família, como primos, tios e avós. Casais buscam resolver suas diferenças de maneira equivocada, não somente sem diálogo e respeito, mas, por vezes, incluindo os filhos nessa dinâmica. Em meio ao conflito, não percebem o quanto as suas atitudes são doloridas para as crianças e os adolescentes que se veem incluídos no dilema, sem qualquer poder aparente de decisão.

Por muitas vezes, os pais, decepcionados e magoados, denigrem a imagem um do outro para os filhos, que começam a sentir medo ou repulsa pelo pai ou pela mãe, e não querem mais a companhia de seus genitores. Usam os filhos como mensageiros ou espiões, discutem na frente deles, dificultam o contato ou as visitas e, pior, os induzem a fazer difíceis escolhas. Não

\footnotetext{
${ }^{3}$ Sobre o conflito, Cecília Briquet (2016, p.61) estabelece que o conflito pode ser latente (real) ou manifestos (aparentes). Às vezes existem as condições para o conflito, mas as partes não se dão conta delas ou não utilizam uma estratégia aberta para a solução de seus problemas, tratando do conflito real. Já o aparente, ou manifesto, é o conflito que as partes trazem superficialmente quando se envolvem em ações hostis entre si.
} 
percebem que tais condutas os deixam ansiosos, tristes e culpados, e criam cicatrizes emocionais que podem, por muitas vezes, ser irreversíveis.

Esta realidade precisa ser modificada. Os pais devem priorizar os filhos e sua formação com dignidade e felicidade. Quando acontece o rompimento da relação entre os genitores, são eles, os filhos, os mais atingidos com a mudança na rotina familiar. Caso os laços sejam desfeitos de forma abrupta, a família pode, por muitos anos, sofrer com conflitos mal administrados. Entretanto, é plenamente possível escolher um caminho diferente em que possam aprender a lidar com o novo contexto familiar, priorizando sentimentos de paz e respeito.

O divórcio consiste em grande desafio emocional para os pais e filhos. Conforme Cezar-Ferreira (2007), sempre haverá uma dor inevitável nas separações, porém, é necessário ter em mente que a relação conjugal pode ser até desfeita, mas a relação entre pais e filhos não se esvai, deve ser mantida através de convívio saudável entre os membros da família reconstituída. A criação, a educação e o cuidado com os filhos são de grande importância e obrigação de todos, é essencial a manutenção de uma relação saudável entre todos os envolvidos.

Contudo, nem sempre estas relações saudáveis são possíveis. O divórcio, a dissolução da união estável ou a disputa por guarda podem iniciar extensas e problemáticas discussões. Em razão disso, tem-se como objetivo considerar as nuances que a mediação de conflitos e as oficinas de parentalidade trazem para os conflitos familiares. É certo que estas atuam de maneira positiva para a caminhada para o consenso entre as partes envolvidas.

Assim, tal método alternativo de solução de conflitos surge como uma opção para uma abordagem mais pacífica e menos adversarial, pois o direito encontra dificuldade de acompanhar as diversas nuances da família na sociedade moderna, conforme salientam Lima e Pelajo (2016, p. 224):

\footnotetext{
A segunda relaciona-se ao evidente anacronismo entre o sistema de adjudicação e a natureza das demandas de família. Contextos familiares são permeados por subjetividade. A qualidade da interação entre os cônjuges/companheiros e demais familiares depende, invariavelmente, das contribuições oferecidas pelas pessoas ao longo da convivência. Atitudes mal compreendidas não raro ensejam reações desproporcionais, que retroalimentam a hostilidade recíproca, em uma escalada destrutiva da relação.
}

Com o aumento da busca pelo Poder Judiciário, a este são levadas demandas inúmeras, para decisão sobre divórcio, guarda compartilhada, pensão alimentícia, dissolução de união 
estável, dentre outras. Tais demandas, pelo que já foi exposto, por muitas vezes carregam sentimentos que podem dificultar a obtenção de entendimento entre as partes. A decisão do Juiz, por si só, não será capaz de dirimir o conflito, ao contrário, jamais o acessará se não houver o enfrentamento de questões intrínsecas e jamais reveladas a olho nu, por serem densas e carregadas de emoções.

Diante destas situações, existe a necessidade de superação dos conflitos, ou seja, entendê-los e transformá-los em oportunidade de melhoria da qualidade dos relacionamentos pessoais ou sociais, o que será possível através da mediação. Conforme Lima e Pelajo (2016, p. 225), é um método integrante de um sistema multiportas de resolução de conflitos, complementar ao Judiciário.

\section{MEDIAÇÃO FAMILIAR}

\subsection{Conceito}

A mediação tem um importante papel nas relações familiares e nos conflitos vivenciados, pois são diversas as demandas judiciais que surgem do convívio familiar, como divórcio, disputa de guarda, pensão alimentícia, dentre outros. Diante da realidade marcada pela instabilidade familiar (SALES, 2007), a mediação pode ajudar os envolvidos a melhorar a qualidade do diálogo entre eles e a conviverem de maneira mais pacífica. Trata-se de um método alternativo de solução de conflitos, em que um terceiro capacitado, através de técnicas específicas de abertura do diálogo, ajuda as partes a comunicarem-se melhor e, eventualmente, a obterem o acordo.

O conflito, conforme Fernanda Tartuce (2015, p. 4), é definido como uma crise na interação humana, é inerente à pessoa humana, pois cada indivíduo possui sua particularidade, vive em seu contexto e sua realidade. O conflito, em si, não é algo negativo, e sim bastante construtivo, porém, por muitas vezes, administrado de maneira errônea, carrega uma conotação negativa. Bem administrado, pode promover satisfação e melhorar a qualidade de vida dos envolvidos. (SALES, 2007).

$\mathrm{Na}$ mediação, o problema é analisado segundo todas as condições que o cercam. A mediação é estruturada de modo a convidar os envolvidos na situação de discordância a reconhecerem o vínculo de interdependência que os une ao problema. (LIMA; PELAJO, 2016). O objetivo da mediação é construir uma nova realidade a partir do tratamento do conflito e da 
conscientização dos envolvidos sobre a capacidade que eles têm de resolver suas próprias questões. O que causa grande êxito nesse método de resolução de conflitos é justamente essa liberdade que as pessoas têm de, em comum acordo, chegar a uma resolução satisfatória.

Trata-se de um procedimento muito eficaz, já que não há melhor decisão que aquela trazida pelas partes. Um acordo elaborado e desenhado pelos envolvidos será por eles, muito mais eficiente e facilmente, cumprido, já que atende aos seus anseios e às suas necessidades. Por meio da entrega de autonomia às partes, a mediação busca a reorganização e reformulação da comunicação entre pessoas, já que, durante uma crise, as partes sentem dificuldade de conversar de forma ordenada e pacífica (SALES, 2007). À medida que os problemas são trazidos à tona, o mediador, figura apta e capaz de mediar um conflito, deve se comportar de maneira atenta e paciente, realizando a escuta ativa. Permanece atento para captar todas as linguagens ali trazidas, não somente as verbais, como também as simbólicas e as não verbais, nada impondo, apenas ajudando as partes a chegarem a um consenso por si só.

A mediação inclui os indivíduos na sociedade, na medida em que aumenta suas responsabilidades, e, como consequência, estes passam a ter voz ativa e capacidade de resolver seus próprios problemas. Desta maneira, apresenta forte impacto na melhoria das condições de vida das pessoas, que passam a exercer a cidadania plena de maneira consciente, trazendo consequências positivas, inclusive, no acesso à justiça por parte da população.

A mediação possui diversas vertentes. A mediação familiar, objeto do presente estudo, é base para toda a metodologia e abordagem das oficinas de parentalidade. (ALDENUCCI, 2012). A família é a instituição que promove o crescimento e a formação das pessoas. Em todos os núcleos familiares existem conflitos, posto que sejam compostos por seres humanos diferentes, cada um com seus defeitos, qualidades e expectativas, os quais, em um conflito, assumem condutas diferentes e, muitas vezes, divergentes.

Diante da dinâmica social vivida e experimentada atualmente, são diversos os modelos familiares, o que terminou a quebra do padrão de papéis preestabelecidos no seio familiar, dando origem ao sofrimento, muitas vezes, devido à ausência de diálogo ou à violência familiar.

Oliveira et al. (2008, p. 34) enfatiza:

Ou seja, ao contrário da visão comumente romantizada de família, o espaço familiar é densamente carregado de conflitos. O nível de intimidade e de disputa dos afetos estimula sentimentos ambíguos de amor e ódio, aliança e competição, proteção e domínio entre todos os membros de uma família. 
Conflitos familiares são marcados por grande carga emocional, pois envolvem sentimentos ocultos, como mágoas, raivas, dores, traumas, entre outros. Eles não surgem repentinamente, mas são construídos por meio de mágoas que as pessoas vão somando ao longo do tempo. Assim, a mediação familiar possui grande importância ao lidar com os conflitos familiares, tão complexos e peculiares, uma vez que tem o papel de ajudar as pessoas, que, inteiramente imbuídas de sentimentos, muitas vezes, confundem seus interesses e atitudes, por estarem envoltas em um sentimento que as fazem restar impossibilitadas de enxergar o conflito de uma maneira ampla, objetiva e com vistas ao futuro.

A mediação busca chegar até o conflito real, como afirmam Lilia Sales e Monica Vasconcelos (2006, p. 76):

A mediação, sobretudo a familiar, objetiva resolver o conflito real, e não o conflito aparente, pois assim estará sendo solucionado o verdadeiro problema. Deste modo, a mediação propõe um trabalho de desconstrução do conflito, fazendo com que os mediados encontrem as reais motivações de suas disputas e as solucionem.

A mediação no âmbito familiar é de grande vantagem, pois esclarece mal-entendidos e valoriza o ser humano em sua individualidade, para além de sua interação social.

\footnotetext{
Diante de todas essas vantagens, a mediação vem crescendo cada vez mais em diversas áreas. Destaca-se a grande eficiência na composição dos conflitos de natureza familiar, visto que representam controvérsias carecedoras de solução pacífica e fundamentada na comunicação. Tal eficiência decorre devido ao modo como a mediação conduz a solução dos problemas, na medida em que propõe uma visão positiva dos conflitos e oportuniza a resolução de querelas pelos próprios mediados, facilitando a continuidade da convivência dos envolvidos. (SALES; VASCONCELOS, 2006, p. 77)
}

O diálogo é essencial para a construção de uma base sólida em uma relação familiar. Quando o divórcio acontece de forma conturbada, é comum verificar diversas reações dos filhos, podendo acarretar desde leves desconfortos, indagações, situações em que eles demandam mais atenção dos pais, até danos graves na sua formação, como depressão, isolamento, alienação parental, baixo rendimento escolar, dentre outras incontáveis consequências.

\subsection{O problema do acesso à justiça}


No Brasil, o acesso à justiça é garantido pela Constituição Federal de 1988, no capítulo de direitos e garantias fundamentais, a qual é apenas o início de um regime democrático igualitário para a população brasileira, mas sabe-se que há muito a percorrer.

Fernanda Tartuce (2015) ressalta que o pressuposto da ideia de justiça para o Direito é a existência de um consenso social sobre as ideias fundamentais de justiça, como, por exemplo, de respeito e proteção da vida humana e da dignidade do homem, a proibição da transformação do homem em objeto, direito à livre formação de personalidade e a proteção do livre arbítrio e da igualdade de tratamento são base para o acesso à justiça e sua concretização.

Importante advertir que a interpretação do acesso à justiça não deve se restringir ao simples ingresso no Poder Judiciário. Em verdade, deve albergar sua visão ampla, ou seja, que a justiça possa ser realizada de modo a incluir as partes, de maneira semelhante, atendendo aos princípios da igualdade, do devido processo legal, dentre outros, produzindo resultados igualmente justos.

Nesse sentido, importante ponderação feita por Aldenucci (2012, p. 118):

Nessa orientação a resposta ideal na mediação não consiste, apenas, em resolver o
problema, mas sim em ajudar a transformar os indivíduos comprometidos com o
crescimento moral. O valor priorizado por essa concepção é a transformação e trata
como fundamental a questão da satisfação individual e o bem-estar coletivo.

Alguns óbices rodeiam os procedimentos judiciais no Brasil, os quais dificultam o acesso à distribuição da justiça, como a formalidade excessiva, a morosidade, altos custos, dificuldade de acesso, e mais ainda, inserido no contexto aqui trazido, por muitas vezes desigual e que não atende aos interesses sociais reais, terminam por não proporcionar o acesso à justiça em seus termos ideais. (TARTUCE, 2015)

O Poder Judiciário brasileiro vem enfrentando inúmeras crises que se prolongam no tempo, principalmente devido à burocracia na resposta às demandas do cidadão. Some-se a isto a crescente conscientização política da sociedade que, hoje em dia, busca muito mais seus legítimos direitos, o que termina por fazer crescer de maneira vertiginosa o número de demandas trazidas à resolução do Poder Judiciário.

Como consequência da realidade contemporânea, há o natural aumento de demandas levadas ao Poder Judiciário. Conforme o levantamento feito pelo Conselho Nacional de Justiça, chamado Justiça em Números, que reuniu dados relativos ao ano de 2016, os assuntos de Direito de Família (família e alimentos), no Brasil, caracterizam o $6^{\circ}$ (sexto) lugar no ranking, totalizando 836.634 (oitocentos e trinta e seis mil, seiscentos e trinta e quatro) demandas em 
2016, correspondendo a 1,97\% (um vírgula noventa e sete por cento) das ações protocoladas no país.

Em relação ao Ceará, verificou-se que, atualmente, tramitam nas Varas de Família da comarca, aproximadamente, 40.265 (quarenta mil, duzentos e sessenta e cinco) processos; sendo a média por juízo de 2.236 (dois mil, duzentos e trinta e seis) processos. No período de janeiro a junho de 2017, foram julgados pelas Varas de Família: 12.893, (doze mil, oitocentos e noventa e três) processos; e entre janeiro e junho de 2017 foi recebida (protocolada) a monta de 12.725 (doze mil, setecentos e vinte e cinco) processos, não podendo o Tribunal de Justiça do Estado do Ceará precisar qual a natureza das demandas, porém todas elas de competência das Varas de Família.

Tal número é alarmante e, apesar de todo o esforço envidado pelos magistrados em apreciar as demandas, demonstra que a sociedade ainda é muito ligada à cultura do litígio, que se encontra engessada no método tradicional de dirimir conflitos apoiando-se na lógica adversarial, em que as partes são pouco ouvidas, na qual há apenas um ganhador. O Estado vem entendendo que o paradigma dessa excessiva busca pelo Poder Judiciário, como única instância capaz de solucionar conflitos, deve mudar, portanto, vem assumindo um movimento de construção de uma nova cultura de resolução consensual, através de um estímulo legal à consensualidade.

A decisão judicial, por vezes, não é capaz de alcançar os reais interesses das partes, apenas limitando-se à subsunção legal. Portanto, resta insatisfatória, dificultando seu cumprimento e, ainda, produzindo mais impasses. Nesse contexto, ressalta-se a importância de meios de composição de conflitos, em especial a mediação, que se baseia no conceito de colaboração, por meio da diminuição da distância entre as partes e da escuta do que elas têm a trazer para a resolução do problema, e, por isso, apresenta um novo paradigma.

Assim, na adoção desse método, não existe perde-ganha, e sim ganha-ganha. Com a construção democrática de um acordo, todos podem encerrar o conflito com suas necessidades atendidas, basta que, para isso, comprometam-se com o propósito da técnica. Adicione-se a isto a possibilidade visível de êxito no cumprimento destes acordos, afinal as próprias partes os construíram, assim estão preparadas para cumpri-los.

Esse novo paradigma vai de encontro à cultura do litígio, enaltecendo uma conduta de cooperação e não de competição entre as partes envolvidas em uma disputa. $\mathrm{O}$ importante é desenvolver um diálogo em que não haja uma única verdade, mas que contemple várias possibilidades (SALES; VASCONCELOS, 2006, p.90) 
De acordo com Fernanda Tartuce (2015), não se deve, porém, atribuir a tal mecanismo e aos demais de composição de conflitos o entendimento de que estes são a resposta única e definitiva para a resolução do preocupante problema do acesso à justiça, pois apenas trata-se de um complemento à abordagem de conflitos, sendo a busca pela solução composta por múltiplas mudanças.

Portanto, a própria manifestação das vontades das partes que culminam em um acordo, em uma mediação, consiste em uma verdadeira justiça. O Poder Judiciário e os outros meios de solução de conflitos devem andar lado a lado para auxiliar a sociedade na resolução de seus problemas.

\section{OFICINAS DE PARENTALIDADE: PIONEIRISMO NA AJUDA NOS CONFLITOS FAMILIARES}

A oficina de parentalidade surgiu inspirada em técnicas utilizadas em outros países como Canadá e Estados Unidos, com a finalidade de reunir, em encontros mensais ou quinzenais, famílias envolvidas em processos judiciais de ruptura conjugal, disputas por guarda de filhos e pagamento de pensão alimentícia, entre outros litígios, para auxiliar pais e filhos (adolescentes e crianças) a lidarem, de maneira mais pacífica e positiva, com as consequências do divórcio, inclusive evitando a alienação parental ${ }^{4}$.

O projeto foi trazido para o Brasil pela Juíza Vanessa Aufiero da Rocha, à época coordenadora do CEJUSC (Centro Judiciário de Resolução de Conflitos) de São Vicente, em São Paulo, onde foi implantado pela primeira vez, com o apoio de uma equipe multidisciplinar. Devido ao resultado positivo, o projeto ganhou corpo e passou a ser encampado pelo Conselho Nacional de Justiça (CNJ), que o adotou como política institucional, de acordo com a Recomendação № 50 de 08/05/2014, e oferece curso a distância para funcionários e juízes, para que se capacitem metodologicamente e adotem uma abordagem mais atenta e pacífica aos problemas possivelmente advindos de um divórcio litigioso conturbado.

A ideia, cujo caráter é preventivo e educativo, tem como principal objetivo levar os pais e filhos a compreenderem que o divórcio é apenas dos pais, e que o vínculo familiar não é rompido com o fim do casamento. Ao contrário, o elo entre aquelas pessoas permanece, em prol da criação dos filhos e da boa convivência entre todos, ou seja, o fim do relacionamento

\footnotetext{
${ }^{4} \mathrm{~A}$ alienação parental consiste em um comportamento dos pais que, reiteradamente, desqualificam um ao outro, levando a uma lavagem cerebral em seus filhos, a ponto de que estes passem a rejeitá-lo ou até mesmo a temê-lo. (SOUSA; BRITO, 2011)
} 
conjugal não deve ser tratado como disputa ou vingança, mas sim como uma nova fase na vida do casal, uma continuação, uma vez que todos permanecerão sendo uma família, apenas com uma formação e uma dinâmica diária diferentes.

A importância do projeto é demonstrada a partir da percepção de que a valorização do diálogo e dos laços familiares é essencial para o entendimento de que os pais devem priorizar o bem-estar dos seus filhos. Dependendo da forma como o fim de um relacionamento é percebido, as consequências para a formação dos filhos são imprevisíveis, pois podem tornarse introspectivos, ou até arredios e agressivos, por atribuírem a si a culpa pelo fim do relacionamento dos pais ou, inclusive, sofrerem alienação parental. Assim, os pais devem preservar a tranquilidade do lar, apenas entendendo a nova dinâmica familiar e se ajustando à nova configuração vivenciada.

O material didático disponibilizado pelo Conselho Nacional de Justiça (CNJ) é composto por cartilhas, vídeos e depoimentos gravados, que são utilizados durante as oficinas. Através da dinâmica realizada com as partes, pretende-se estimular uma reflexão sobre o entendimento do conflito vivido e a importância do diálogo, assim como a busca de um novo movimento, de pacificação e entendimento familiar.

Devido ao retorno positivo, o projeto oficina de pais e filhos foi se difundindo por todo o estado de São Paulo e, posteriormente, por todo o Brasil. Atualmente, é realizado em diversos Tribunais ao redor do país. Em Fortaleza, as reuniões ocorrem a cada quinze dias, desde 2014, no Fórum da cidade, tornando-se referência de qualidade para todo o país (TJCE, 2015), e são geridas pelo CEJUSC local, com apoio do Núcleo Permanente de Métodos Consensuais de Solução de Conflitos (Nupemec) do Tribunal de Justiça do Ceará (TJCE).

Em Fortaleza, foram realizados, durante os anos de 2015 e 2016, 31 encontros, contemplando, no total, 701 adultos, 286 crianças e 152 adolescentes. Em 2017, o trabalho está sendo expandido para as extensões do Centro Judiciário na Capital, localizados na Universidade de Fortaleza (UNIFOR), Faculdade Farias Brito (FFB) e Defensoria Pública do Estado (IBDFAM, 2017). O desempenho do projeto no estado do Ceará vem sendo reconhecido como referência no Brasil, inclusive tendo recebido servidores de Tribunais de outros estados para treinamento e visita às dependências onde são realizadas as oficinas, para replicarem em seus respectivos centros judiciais. (TJRN, 2017).

Atualmente, está à frente das reuniões uma equipe formada por psicólogos, pedagogos, assistentes sociais e profissionais do Direito. As oficinas são divididas entre pais (homens e mulheres), adolescentes e crianças, para que a abordagem seja feita de maneira mais adequada 
a cada uma das percepções vividas. Como a iniciativa busca ajudar os pais a estabelecerem uma relação construtiva e a transmiti-la para os filhos, lança mão de atividades voltadas aos pais e outras diferentes para os filhos, sempre dando a oportunidade para que estes externem seus sentimentos e pensamentos.

Como as crianças possuem mais facilidade de externar sentimentos através do lúdico, com elas, leem-se livros, fazem-se fantoches e pintura. Já para os adolescentes utilizam-se músicas, rodas de conversa e escrita, e os adultos assistem palestras, depoimentos e fazem leituras, pois o modelo adotado possui um viés mais preventivo e educativo, já que é destinado ao esclarecimento sobre as causas e consequências da inclusão desnecessária do filho no conflito, como a alienação parental. (CNJ, 2017)

A intenção precípua é transmitir aos pais as técnicas apropriadas de comunicação na família, proporcionar ensinamentos sobre as consequências dos conflitos para os filhos, informações sobre o que é alienação parental, guarda, visitas e alimentos, bem como o entendimento de que o relacionamento pode ter chegado ao fim, mas que a relação de parentalidade com os filhos sempre permanecerá.

Quanto aos filhos, a oficina busca esclarecer sobre os sentimentos mais comuns vivenciados pelas crianças e adolescentes, como as consequências do fim do relacionamento de seus pais, quando o pai ou a mãe faz perguntas excessivas ao término de cada visita, quando é usado como mensageiro entre os pais, e, principalmente, quando se sentem culpados por continuar a gostar do genitor que saiu de casa. Também se sentem culpados por não tomarem partido entre os pais, que, muitas vezes, cobram essa atitude, e, por fim, por não presenciarem as discussões dos pais, entre outros.

Como as demandas de família são numerosas, o projeto prioriza atender aos processos enviados pelos juízes de família que entendem aos conflitos mais litigiosos, sendo essa convocação feita com base nos princípios constitucionais do melhor interesse da criança e da dignidade humana. Porém, caso as partes tenham conhecimento do projeto e queiram participar, podem solicitar, na própria vara em que o processo tramita, o envio do processo ao CEJUSC, para inclusão no encontro da oficina. (TJCE, 2015).

A valorização do caráter preventivo e educativo do conflito faz parte de uma política pública de transformação de uma sociedade conflituosa e violenta, por meio da valorização da família. Instrumentos como a oficina têm grande potencial de garantir aos cidadãos um lar estável para o seu pleno e saudável desenvolvimento. 
Neste contexto, é de extrema importância a política pública de prevenção e resolução de conflitos familiares, instituída pelo Conselho Nacional de Justiça através das Oficinas de Parentalidade, pois os temas nelas tratados importam em orientações e alertas imprescindíveis aos pais em processo de ruptura. Além do mais, o projeto possibilita aos filhos um ambiente confiável para expor suas angústias naturais decorrentes da separação dos genitores e confere a estes estratégias para melhor enfrentar essa fase. (SILVA et al., 2015, p.8)

Em relação ao processo judicial, encontram-se diversos benefícios, pois os processos tendem a se arrastar por longos anos sem julgamento, assim, muitas pessoas se descontentam, perdem as esperanças, sem contar que um simples divórcio pode ensejar outras ações, como revisionais de pensão alimentícia, dentre outras. A situação perdura no tempo e, muitas vezes, ao prolatar uma sentença e aplicar a lei, o juiz não consegue alcançar o que as partes, de fato, desejam. Ao contrário, quando há possibilidade de abertura para o diálogo entre as partes, elas se abrem a outras possibilidades, pensam no futuro e testam a realidade que viverão, escutam e sentem empatia uma pela outra, o que facilita sobremaneira a construção de um acordo em sede de audiência de conciliação.

Diante da tendência de judicialização vivida atualmente no Brasil, as pessoas tendem a entregar ao Poder Judiciário a competência para a resolução de seus problemas, dissabores e mágoas. Por meio da oficina de parentalidade, é possível o entendimento de que eles podem, ao se colocar no lugar do outro, dar o primeiro passo na caminhada pela resolução dos seus próprios conflitos, através do diálogo e da comunicação, concretizando o acesso à justiça na sua forma mais genuína.

\section{CONCLUSÃO}

Com as mudanças sociais, as famílias sofreram alterações em sua estrutura. A dinâmica familiar também mudou, tornando-se presente a parentalidade. Muitas famílias padecem pela ausência de diálogo e do enfrentamento positivo dos problemas, o que pode ocasionar diversas consequências, como a ruptura dos laços familiares, através da dissolução de união estável e do divórcio, por exemplo.

Por não saberem lidar com as instabilidades que a mudança acarreta em suas vidas, as pessoas envolvidas no conflito assumem posição de acirramento, competição, frustração e raiva, dentre outros sentimentos negativos. A mediação familiar demonstra sua importância na medida em que, por meio de técnicas especializadas, ajuda as pessoas a olharem para o conflito de uma maneira mais positiva, cooperativa e com vistas ao futuro, viabiliza o diálogo e cria a 
oportunidade de construção de um acordo que seja satisfatório para todos os envolvidos no problema.

As oficinas de parentalidade, objeto do presente artigo, utilizam as técnicas de mediação, em reuniões mensais ou quinzenais, a fim de auxiliar as partes a romperem a barreira do sofrimento e priorizarem um bom relacionamento com o(a) ex-companheiro(a) e os filhos advindos da relação, bem como todos os outros envolvidos no conflito, com vistas à preservação de uma convivência pacífica e construtiva.

O projeto tem encontrado retornos positivos em todo o Brasil, e sua importância é demonstrada quando ajuda as partes a viabilizar o diálogo e oportunamente contribuem para o processo em trâmite, já que, proporcionada a quebra de barreiras de sentimentos e mágoas, iniciam a caminhada para um futuro acordo entre as partes.

Como consequência da realidade contemporânea, há um aumento significativo de procura pela prestação jurisdicional. O CNJ, atento a esta demanda, promove, por intermédio de diversas frentes, a mudança de paradigma da cultura do litígio para a cultura do consenso. $\mathrm{O}$ projeto, objeto do presente artigo, conforme frisado anteriormente, é apoiado pelo órgão, que fornece cartilhas e treinamento aos servidores, para que estes possam replicá-lo em diversas cidades do país.

Apesar de demonstrada a importância do projeto para a busca de uma nova visão de acesso à justiça, é certo que ainda há muito a ser conquistado, e o caminho a ser percorrido é longo e cheio de percalços. Afinal, ainda são contabilizados mais de 800.000 (oitocentos mil) processos em trâmite no Brasil, e este número aumenta a cada dia. Cabem, portanto, ao Poder Judiciário a constante preocupação e a consequente criação de políticas públicas de incentivo à sociedade, para o entendimento do que é a cultura do consenso e da cooperação. Importante também que se envidem esforços para a conscientização das diversas classes que formam o sistema de Justiça, como advogados, promotores, juízes, defensores públicos, dentre outros, para que esclareçam às partes a importância do diálogo, assim como conheçam e utilizem os métodos alternativos de solução de conflitos em seu dia a dia, de maneira natural.

\section{REFERÊNCIAS}

ALDENUCCI, Lidercy Prestes. Mediação de conflitos familiares. In BRAGA NETO, Adolfo. SALES, Lilia Maia de Moraes. Aspectos atuais sobre a mediação e outros métodos extra e judiciais de resolução de conflitos. Rio de Janeiro: GZ Editora, 2012. 
BAHIA. Tribunal de Justiça. Ceará: Oficina promove método inovador na solução de conflitos familiares. Disponível em: <http://www5.tjba.jus.br/infanciaejuventude/index. php?option=com_content\&view $=$ article \&id=1485: ceara-oficina-promove-metodo-inovadorna-solucao-de-conflitos-familiares\&catid=2:noticias\&Itemid=13>. Acesso em: 01 ago. 2017.

BAUMAN, Zygmunt. Modernidade líquida. Tradução de Plínio Dentzien. Rio de Janeiro: Zahar, 2001.

BRASIL. Constituição de (1988). Constituição da República Federativa do Brasil. Brasília, DF, Senado Federal, 1988.

BRIQUET, Enia Cecilia. Manual de mediação: teoria e prática na formação do mediador. Petrópolis, RJ: Vozes, 2016.

CEARÁ. Tribunal de Justiça. Centro Judiciário de Fortaleza promove primeira Oficina Pais e Filhos de 2017. Disponível em: <http://www.tjce.jus.br/noticias/centro-judiciario-defortaleza-promove-primeira-oficina-pais-e-filhos-de-2017/>. Acesso em: 02 de ago. 2017.

Coordenadoria da Infância e da Juventude do Tribunal de Justiça. Oficina de pais e filhos no Fórum de Fortaleza auxilia famílias a enfrentar conflitos conjugais. Disponível em: <http://portais.tjce.jus.br/cijce/oficina-de-pais-e-filhos-no-forum-de-fortaleza-auxiliafamilias-a-enfrentar-conflitos-conjugais/> . Acesso em: 02 ago. 2017.

Oficina Pais e Filhos no Ceará é referência para outros estados. Disponível em: $\overline{<\mathrm{http}: / / w w w . t j c e . j u s . b r / n o t i c i a s / o f i c i n a-p a i s-e-f i l h o s-n o-c e a r a-e-r e f e r e n c i a-p a r a-o u t r o s-~}$ estados/>. Acesso em: 02 ago. 2017.

CEZAR-FERREIRA, Verônica A da Motta. Família, separação e mediação: uma visão psicojurídica. São Paulo: Método, 2007.

CONSELHO NACIONAL DE JUSTIÇA - CNJ. Recomendação no 50 de 08/05/2014.

Recomenda aos Tribunais de Justiça, Tribunais Regionais do Trabalho e Tribunais Regionais Federais realização de estudos e de ações tendentes a dar continuidade ao Movimento Permanente pela Conciliação. Disponível em: <http://www.cnj.jus.br/busca-atosadm?documento=1241>. Acesso em: 02 ago. 2017.

Oficina para orientar pais e filhos chega à $24^{\mathrm{a}}$ edição em Fortaleza. Disponível em: <http://www.cnj.jus.br/noticias/judiciario/82397-oficina-para-orientar-pais-e-filhoschega-a-24-edicao-em-fortaleza>. Acesso em: 01 ago. 2017.

GAGLIANO, Pablo Stolze. PAMPLONA FILHO, Rodolfo. Novo curso de direito civil. 6. 7. ed. São Paulo: Saraiva, 2017.v.6.

INSTITUTO BRASILEIRO DE DIREITO DE FAMILIA - IBDFAM. Extensão do Cejusc na Universidade de Fortaleza realiza primeira "Oficina Pais e Filhos". Disponível em: <http://www.ibdfam.org.br/noticias/na-midia/13786>. Acesso em: 01 ago. 2017. 
Oficina de Pais e Filhos-Projeto pioneiro no Brasil pretende ajudar pais e filhos envolvidos em divórcios litigiosos. Disponível em: <http://www.ibdfam.org.br/noticias/ 4949/novosite>. Acesso em: 31 jul. 2017.

LIMA, Evandro Sousa e. PELAJO, Samantha. A mediação nas ações de família. In: A mediação no novo código de processo civil. ALMEIDA, Diogo Assumpção Rezende de; PANTONA, Fernanda Medina; PELAJO, Samantha (Coord.). 2. ed. Rio de Janeiro: Forense, 2016.

OLIVEIRA, Maria Coleta et al. Mediação familiar transdisciplinar: uma metodologia de trabalho em situações de conflito de gênero. São Paulo: Summus, 2008.

RIO GRANDE DO NORTE. Tribunal de Justiça. Servidoras do Cejusc conhecem oficinas de parentalidade no TJCE. Disponível em: <http://www.tjrn.jus.br/index.php/comunicacao /noticias/11892-servidoras-do-cejusc-conhecem-oficinas-de-parentalidade-no-tjce>. Acesso em: 02 ago. 2017.

ROSENBERG, Marshall B. Comunicação não violenta: técnicas para aprimorar relacionamentos pessoais e profissionais. São Paulo: Ágora, 2006.

SALES, Lilia Maia de Morais. Mediação de conflitos: família, escola e comunidade. Florianópolis: Conceito Editorial, 2007.

; VASCONCELOS, Mônica Carvalho. Mediação familiar: um estudo histórico-social das relações de conflitos nas famílias contemporâneas. 13. ed. Fortaleza: Expressão Gráfica e Editora, 2006.

SILVA, Luciana Maria da et al. Oficinas de parentalidade. Revista Participação, Brasília, Ano 15, n.27, jul. 2015. Disponível em: <http://periodicos.unb.br/index.php/participacao/ article/view/15269>. Acesso em: 02 ago. 2017.

SOUSA, Analícia Martins de; BRITO, Leila Maria Torraca de. Síndrome de alienação parental: da teoria Norte-Americana à nova lei brasileira. Psicologia Ciência e Profissão, v. 31, n. 2, 2011.

TARTUCE, Fernanda. Mediação nos conflitos civis. 2. ed. Rio de Janeiro: Forense; São Paulo: Método, 2015. 